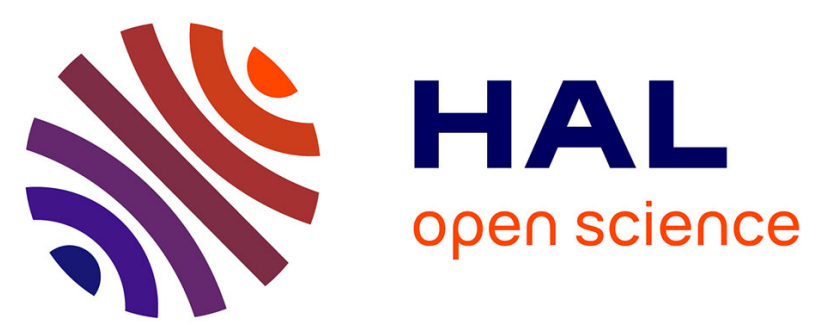

\title{
Thermal spin-crossover with a large hysteresis spanning room temperature in a mononuclear complex.
}

\author{
Élodie Tailleur, Mathieu Marchivie, Nathalie Daro, Guillaume Chastanet, \\ Philippe Guionneau
}

\section{- To cite this version:}

Élodie Tailleur, Mathieu Marchivie, Nathalie Daro, Guillaume Chastanet, Philippe Guionneau. Thermal spin-crossover with a large hysteresis spanning room temperature in a mononuclear complex.. Chemical Communications, 2017, 53 (35), pp.4763-4766. 10.1039/c7cc01806a . hal-01519740

\author{
HAL Id: hal-01519740 \\ https://hal.science/hal-01519740
}

Submitted on 3 Mar 2021

HAL is a multi-disciplinary open access archive for the deposit and dissemination of scientific research documents, whether they are published or not. The documents may come from teaching and research institutions in France or abroad, or from public or private research centers.
L'archive ouverte pluridisciplinaire HAL, est destinée au dépôt et à la diffusion de documents scientifiques de niveau recherche, publiés ou non, émanant des établissements d'enseignement et de recherche français ou étrangers, des laboratoires publics ou privés. 


\section{Journal Name}

\section{Thermal spin-crossover with a large hysteresis spanning room temperature in a mononuclear complex $\dagger$}

Received 00th January 20xx, Accepted 00th January 20xx

DOI: $10.1039 / \times 0 \times x 00000 x$

\author{
E. Tailleur, M. Marchivie, N. Daro, G. Chastanet and P. Guionneau*
}

www.rsc.org/

Large hysteresis centered around room temperature represent one of the mandatory goals of researches on functional switchable materials. In the thoroughly studied field of spin-crossover, such behaviour appears very rare and essentially concerns coordination networks. A new compound showing a large spin-crossover hysteresis spanning room temperature demonstrates in a definitive manner that this goal is achievable in molecular discrete compounds without damaging the single-crystal character.

Despite targeted amongst the main goals of the Spin-Crossover (SCO) materials investigations, ${ }^{1}$ large thermal hysteresis still appear relatively uncommon. This is particularly evident if referring to SCO hysteresis spanning room temperature that are nevertheless clearly a prerequisite to any applicative willingness. ${ }^{2}$ Recent efforts to tabulate in an exhaustive manner the features of all the hysteresis reported have revealed to be an almost unreachable aim, on the admission of the authors themselves, due to the diversity of the situations to induce the hysteresis, the peculiarity of each compound - as regarding for example the roles of solvents of structural characteristics and of the fragility of the samples - as well as sometimes the lack of full or reliable characterizations of the hysteresis features. ${ }^{3-5}$ However, known SCO compounds showing hysteresis are probably only a few tenths so far. When focusing on large hysteresis spanning room temperature, this number decreases to a few units almost always belonging to the class of the SCO coordination polymers. Here we report on a mononuclear SCO complex showing a large hysteresis spanning room temperature. As a general matter, the SCO hysteresis is defined by the difference between the temperatures at which the ratio of High-Spin (HS) and Low Spin (LS) metallic centres is 50:50 in the cooling mode $\left(T_{1 / 2} \downarrow\right)$ and in the warming mode $\left(T_{1 / 2} \uparrow\right)$ leading to the temperature width denoted $\Delta \mathrm{T}$. In order to clarify the discussion, let us consider room temperature as being in the range $283-303 \mathrm{~K}$ and large hysteresis corresponding to $\Delta \mathrm{T}>20 \mathrm{~K}$.

CNRS, Univ. Bordeaux, ICMCB, UPR 9048, 87 avenue du Dr A. Schweitzer, F-33608 Pessac, France.

E-mail: philippe.guionneau@icmcb.cnrs.fr

+ Electronic Supplementary Information (ESI) available: Squid measurements on subsequent cycles, Squid measurements with different cooling rates, Powder X-ray diffraction. See DOI: 10.1039/x0xx00000x
The latter is not at all a drastic view since it can even be considered insufficient for practical applications ${ }^{6}$ and the former is the usual range delimitation as for example in crystallography data base to qualify ambient conditions. The average between $T_{1 / 2} \downarrow$ and $T_{1 / 2} \uparrow$ is subsequently abbreviated $T_{\text {hlc }}$, for Temperature of Hysteresis Loop Centre, and should ideally falls into the room temperature range as defined above. First, coordination polymers offer examples of large hysteresis loops. Among them the triazole-based iron(II) 1D coordination polymers of general formula $\left[\mathrm{Fe}(\mathrm{R}-\mathrm{trz})_{3}\right] . \mathrm{A}_{2}$.solvent $(\mathrm{R}-\mathrm{trz}=$ functionalized 1,2,4-triazole ligand) certainly form the most studied SCO family in the literature notably because since the early stage of its discovering relatively large hysteresis were obtained. ${ }^{1 a, 7}$ This family has been, and probably still is, the flagship of the applicative ambition of the SCO field. Recent remarkable reviews give an overall view of the SCO features of about 80 compounds within this family; ${ }^{8}$ only four of them apparently meeting the above criteria (i.e. $\mathrm{T}_{\text {hlc }}$ within $283-303 \mathrm{~K}$ and $\Delta \mathrm{T}>20 \mathrm{~K})$. Notably, the initially reported compound $\left[\mathrm{Fe}(\mathrm{Htrz})_{0.85}\left(\mathrm{NH}_{2} \text {-trz }\right)_{0.15}\right]\left(\mathrm{ClO}_{4}\right)_{2} \cdot \mathrm{nH}_{2} \mathrm{O}(\mathrm{Htrz}=1 \mathrm{H}-1,2,4 \text {-triazole })^{7}$ matches the criteria $\left(T_{\mathrm{hlc}}=296 \mathrm{~K}, \Delta \mathrm{T}=22 \mathrm{~K}\right.$ ) but its doping nature makes it not easily achievable. Furthermore, one of the weaknesses of this family comes from the instability of the compounds and the poor reproducibility of the hysteresis loop features often attributed to the loss of solvent and the weak crystallinity that also prevent from deeper investigations. One of the most stable of them, $\left[\mathrm{Fe}(\mathrm{Htrz})_{2}(\operatorname{trz})\right]\left(\mathrm{BF}_{4}\right)$, incidentally does not contain solvent and shows remarkably reproducible SCO hysteresis features. ${ }^{9}$ This compound has therefore concentrated main part of the efforts from the community around the design and the exploration of innovative route towards SCO devices, as shown by recent results. ${ }^{10}$ Though, its hysteresis loop does not span room temperature at all ( $T_{\text {hlc }}=365$ $\mathrm{K}, \Delta \mathrm{T}=40 \mathrm{~K}$ ). Recently, a new series of $1 \mathrm{D}$ iron(II) SCO coordination polymers built with $\mathrm{N}_{2} \mathrm{O}_{2}$ coordinating Schiff-baselike ligands have been reported. ${ }^{11}$ Among it, at least one compound meets the above criteria ( $\mathrm{T}_{\mathrm{hlc}}=284 \mathrm{~K}, \Delta \mathrm{T}=88 \mathrm{~K}$ ), but it is only available in powder form and consequently not fully structurally characterized. Note that one of the difficulties encountered when comparing hysteresis loops is that the width may also strongly depend on the sample form (single-crystal, 
powder, films). This is not the topic here to tackle that question but, clearly, working on single-crystals leads to narrower hysteresis. Elsewhere, the 3D coordination network [ $\mathrm{Fe}(\mu-$ pyrazine) $\left.\mathrm{Pt}(\mu-\mathrm{CN})_{4}\right]$ is probably one of the most suitable system since it displays a large hysteresis spanning room temperature ( $T_{\text {hlc }}=297 \mathrm{~K}, \Delta \mathrm{T}=24 \mathrm{~K}$ ) providing however that a preliminary dehydration is performed. Contrary to the coordination polymers, the cohesion of molecular-complexes solids is mainly based on non-covalent interactions. ${ }^{12}$ Notably, the paramount role of hydrogen bonds on SCO features is well documented. ${ }^{13}$ The relative weakness of hydrogen bonds in comparison with covalent linkers does not prevent at all the observation of hysteresis and some mononuclear materials are even known to exhibit large hysteresis. ${ }^{3-6}$ However, in the literature survey of SCO thermal hysteresis, no mononuclear system strictly obeys to both of the defined criteria. The most pertinent compound found in the literature in relation to the present discussion, is certainly an iron(II) imidazole-based complex that almost fits the criteria $\left(T_{\text {hlc }}=279 \mathrm{~K}, \Delta \mathrm{T}=70 \mathrm{~K}\right)^{14}$ but the lack of characterization, notably due to the crack of the sample in LS, has probably limited its impact in the SCO field so far. Other mononuclear compounds closest to these criteria seem to belong to iron(III) systems as for instance in the interesting cases of one thiosemicarbazone-based complex ${ }^{15}\left(T_{\text {hlc }}=313 \mathrm{~K}\right.$, $\Delta \mathrm{T}=39 \mathrm{~K})$ and one salicyladimine-based complex ${ }^{6 \mathrm{a}}\left(\mathrm{T}_{\mathrm{hlc}}=247 \mathrm{~K}\right.$, $\Delta T=76 \mathrm{~K}$ ). In the first case, however, the hysteresis loop presents an asymmetrical shape that is not fully explained notably due to the lack of crystal structures. In the second case, the asymmetric shape and the discrepancy between the first and the subsequent hysteresis loops were attributed to solvent loss effects and impurities, the cracks of the samples at the SCO preventing from a full description of the compound behaviour. This quick tour of the SCO compounds enhances the relevance and originality of the mononuclear iron complex reported here since it exhibits a reproducible single-crystal to single-crystal SCO with a well-shaped large hysteresis loop spanning room temperature.

The synthesized compound, ${ }^{\ddagger}\left[\mathrm{Fe}(\mathrm{PM}-\mathrm{PEA})_{2}(\mathrm{NCSe})_{2}\right]$ with PMPEA $=\mathrm{N}-\left(2^{\prime}\right.$-pyridylmethylene $)-4-($ phenylethynyl)aniline, shows a reversible first-order SCO with $\mathrm{T}_{1 / 2} \downarrow=266 \mathrm{~K}$ and $\mathrm{T}_{1 / 2} \uparrow=307 \mathrm{~K}$ (Fig. 1). ${ }^{\S}$ The SCO features therefore perfectly reach the above defined criteria $\left(T_{\text {hlc }}=286 \mathrm{~K}, \Delta \mathrm{T}=41 \mathrm{~K}\right)$. In addition the hysteresis loop is perfectly reproducible over successive thermal cycles (ESI). Moreover, this hysteresis width is the stable one since it is not influenced by a variation of temperature scan rate from 2 to $5 \mathrm{~K} / \mathrm{mn}$. It is worth to note that the sulphur-analogue compound, $\left[\mathrm{Fe}(\mathrm{PM}-\mathrm{PEA})_{2}(\mathrm{NCS})_{2}\right]$, is known to show a large hysteresis at lower temperature with a similar hysteresis width $\left(T_{\text {hlc }}=211 \mathrm{~K}, \Delta \mathrm{T}=42 \mathrm{~K}\right) \cdot{ }^{16}$ Consequently, the replacement of $\mathrm{S}$ by Se does not affect the hysteresis width but drastically increases the SCO temperatures by $75 \mathrm{~K}$. This increase appears perfectly on line with early results obtained on similar iron(II) compounds showing temperature increases of $40-60 \mathrm{~K}$ by substitution of $\mathrm{S}$ by Se. ${ }^{16}$ In these cases however, no data was available about the potential influence of the substitution on the hysteresis and overall the determination of SCO temperatures was not performed using the same method but by a combination of squid measurements, calorimetry and X-Ray diffraction which prevented from an accurate comparison of the temperature shifts due to the sole $S$ to Se replacement. This replacement is commonly reported in the literature without a clear trend on the effect of this substitution on the cooperativity. ${ }^{18}$ In the present case, the retaining of the hysteresis width is in favour of a conservation of cooperativity. Additionally, light irradiation was applied at low temperature on the compound and no lightinduced effect was observed. The absence of photo-induced effect on the selenium derivative while a small effect was observed on the sulfur derivative ${ }^{16 b}$ agrees with the inverse energy gap law ${ }^{19}$ and the T(LIESST) vs $T_{1 / 2}$ database. ${ }^{20}$

Fig. 1 Temperature dependence of $\chi_{\mathrm{MT}}$ as a function of temperature

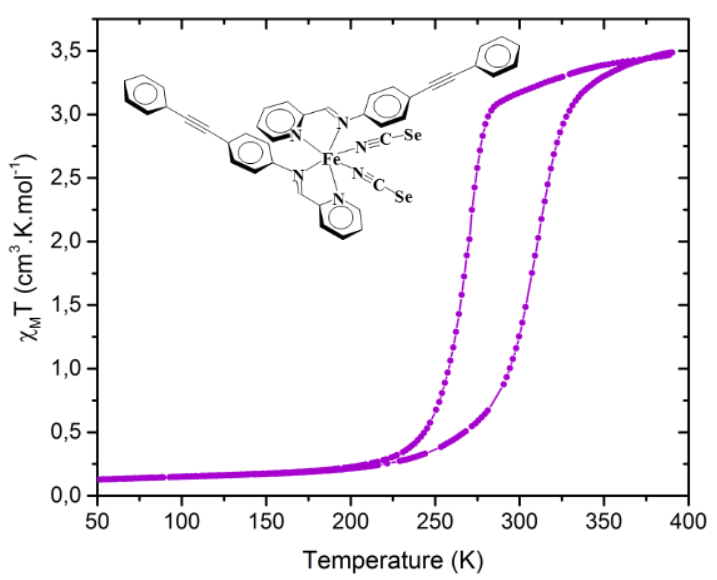

from SQUID measurements for a polycrystalline assembly of [Fe(PM$\left.\mathrm{PEA})_{2}(\mathrm{NCSe})_{2}\right]$. The molecular scheme is inserted.

Single-Crystal X-Ray Diffraction (SCXRD) ${ }^{\S \S}$ has allowed to determine the crystal structures in the HS state $(300 \mathrm{~K})$ and in the LS state $(230 \mathrm{~K})$. The coordination sphere geometry description is known to be a relevant tool to determine the spin state. ${ }^{5,12,16 a, 21}$ In the present case, the average $\mathrm{Fe}-\mathrm{N}$ bond lengths (2.153(5) $\AA$ at $300 \mathrm{~K}$ and $1.967(6) \AA$ at $230 \mathrm{~K}$ ), and the octahedron volume (12.88 $\AA^{3}$ and $9.99 \AA^{3}$ respectively) unambiguously confirm the spin states. Note that at $300 \mathrm{~K}$ the compound is still not entirely in the HS state. The root mean square deviation (RMSD) of the atomic positions within the molecular complex in the HS and the LS states is quite high $(0.462 \AA)$ revealing large differences between the corresponding molecular structures (Fig 2). As for its sulphur analogue, $\left[\mathrm{Fe}(\mathrm{PM}-\mathrm{PEA})_{2}(\mathrm{NCSe})_{2}\right]$ undergoes a structural transition associated to the SCO from monoclinic $\mathrm{P} 22_{1} / \mathrm{c}$ (HS) to orthorhombic Pccn (LS). Note that, with regard to the literature on structural transitions in SCO compounds, 4,12,21,22 the increase of symmetry from HS to LS appears a very rare situation since lowering the temperature generally lead to a lower symmetry. Since it is identical in both compounds, this unusual transition is probably not connected to the huge shift of the SCO temperatures from the $\mathrm{S}$ to the Se compounds. It is therefore not the topic to further comment here that point but first it signs the structural peculiarity of the $\left[\mathrm{Fe}(\mathrm{PM}-\mathrm{PEA})_{2}(\mathrm{NCX})_{2}\right]$ 
compounds and then it shows that the substitution of $\mathrm{S}$ by Se has not altered this feature. The RMSD criterion clearly indicates the vicinity of the $\mathrm{S}$ and Se molecular structures both in HS (0.057 $\AA$ ) and LS (0.066 ̊̊) underlying the isostructural character of both compounds (Fig 2).
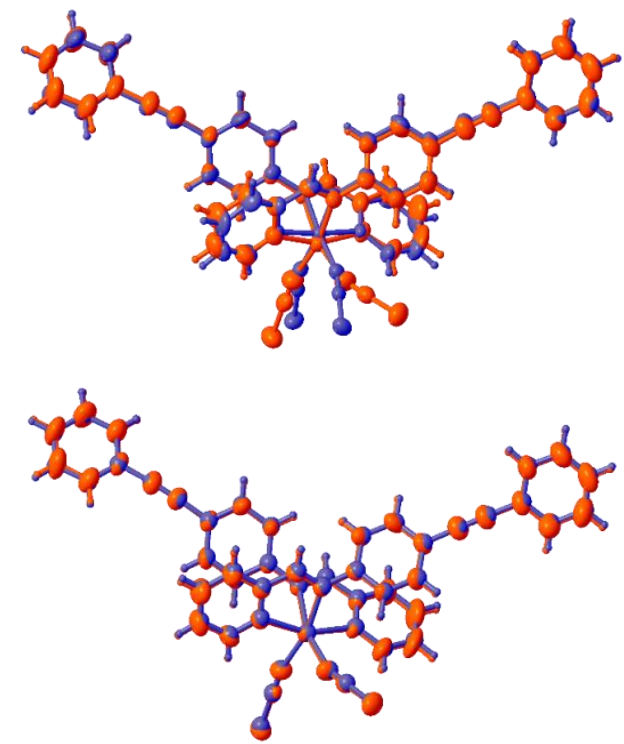

Fig. 2 Superposition of the molecular structures from SCXRD comparing the atomic positions (up) between the HS (red) and LS (blue) states in $\left[\mathrm{Fe}(\mathrm{PM}-\mathrm{PEA})_{2}(\mathrm{NCSe})_{2}\right]$ and (down) between [Fe(PM-PEA $\left.)_{2}(\mathrm{NCSe})_{2}\right]$ (red) and $\left[\mathrm{Fe}(\mathrm{PM}-\mathrm{PEA})_{2}(\mathrm{NCS})_{2}\right]$ (blue) in $\mathrm{HS}$.

The crucial role of the hydrogen bonds on the SCO features is largely documented in discrete molecular compounds. ${ }^{11-16,21-23}$ An overall view of the intermolecular interactions is provided by the Hirshfeld surface analysis through fingerprints representations (Figure 3). ${ }^{24}$ First, the latter confirm that the intermolecular interactions in the present compound are mainly formed through $\mathrm{H}$ atoms; Se... $\mathrm{H}$ contacts playing a significant role as known for $\mathrm{S} . . . \mathrm{H}$ in the sulphur analogue. ${ }^{16}$ The similitude between the fingerprints of the sulphur and selenium analogues clearly shows that the replacement has not affected the geometry of the intermolecular interactions network. Since this statement is true in the HS and LS phases, it also clearly evidences that the transition is identical in both compounds. Consequently, it is possible to conclude here without any doubts that the replacement of $\mathrm{S}$ by Se has no significant effects on the geometry of the intermolecular interactions. This is coherent with the absence of a large effect on the hysteresis width. However, a slight loss of the transition steepness can be noted on the magnetic behaviour in the Se compound on heating. This loss results in slightly more asymmetric hysteresis for the Se than for the $\mathrm{S}$ analogue, as already observed in some iron(III) compounds, ${ }^{13 a}$ which is probably linked to very subtle structural and/or microstructural characteristics. Elsewhere, in the selenium compound like in the sulphur one, the topology of the intermolecular interactions appear clearly different in HS and LS; shortest intermolecular $\mathrm{H}$... H distances being evidenced

in the HS crystal packing. This structural feature is probably linked to the unusual transition shown by this compound.

(a) $\left[\mathrm{Fe}(\mathrm{PM}-\mathrm{PEA})_{2}(\mathrm{NCSe})_{2}\right]$

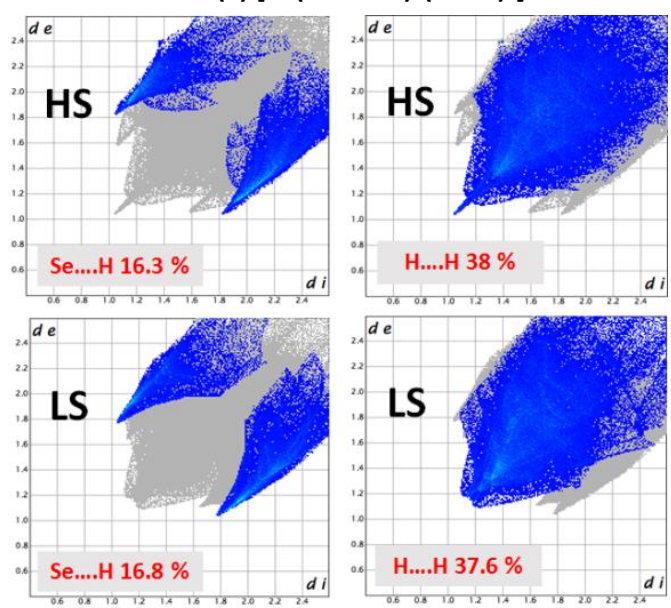

(b) $\left[\mathrm{Fe}(\mathrm{PM}-\mathrm{PEA})_{2}(\mathrm{NCS})_{2}\right]$
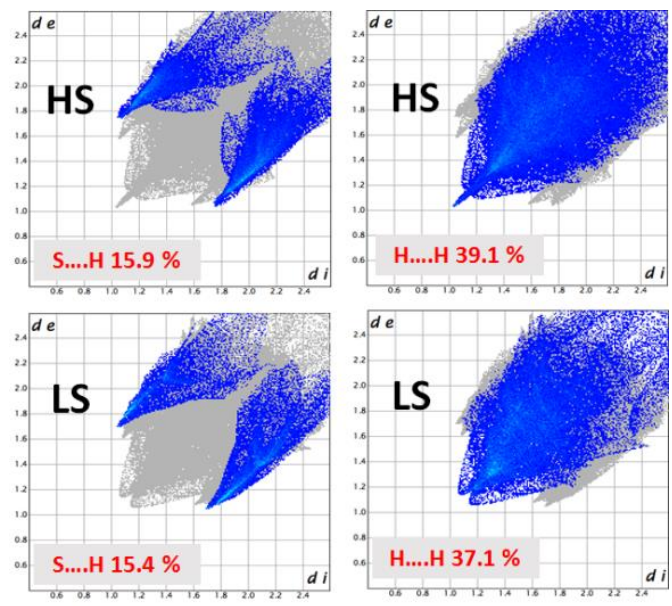

Fig. 3 Fingerprints of the intermolecular interactions in (a) $[\mathrm{Fe}(\mathrm{PM}-$ $\left.\mathrm{PEA})_{2}(\mathrm{NCSe})_{2}\right]$ and (b) $\left[\mathrm{Fe}(\mathrm{PM}-\mathrm{PEA})_{2}(\mathrm{NCS})_{2}\right]$ within the HS (up) and LS (down) crystal packings from Single-Crystal X-ray Diffraction data. Grey zones represent all the interactions and the blue zones account for the corresponding selected interaction; i.e. Se...H (left) and H...H (right).

In addition, preliminary measurements seems to show that changing the form of the sample from powder to single-crystal does not affect the hysteresis width that remains similar but it modifies the temperatures of transition (see ESI). Replacing the powder in the magnetic measurements by a large single-crystal has indeed no noteworthy effects on the measured hysteresis while the SCO temperatures are shifted by $15 \mathrm{~K}$ to lower temperatures. Since powders and single-crystal are isostructural in this case (ESI), the main differences are therefore linked to the size of the coherent domains. Changing the size of the sample could therefore be seen as a way to modulate the SCO temperatures without changing the hysteresis width in this compound. However, these observations point firstly the need for an in-depth microstructural investigation and secondly the global caution one has to care of while comparing results obtained on different kind of 
samples. The detailed investigation aiming the elucidation of the SCO mechanism at various physical scales notably including structural movies ${ }^{23}$ as well as microstructural studies are presently underway.

To summarize, the synthesis of [Fe(PM-PEA $\left.)_{2}(\mathrm{NCSe})_{2}\right]$ leads to one of the very rare compound showing a SCO spanning room temperature and definitively confirms that this goal is achievable even in the case of mononuclear complexes. Besides, the structural transition associated to the large hysteresis retains in this case the single-crystal form of the sample. Consequently, the crystal structures determined in the HS and LS states have given access to unusual data to describe the $\mathrm{S}$ to Se replacement effects on the cooperativity of SCO materials.

The authors gratefully acknowledge the Agence Nationale de la Recherche for financial support under grant ANR FemtoMat 13-BS04002 as well as the Region Nouvelle Aquitaine. The University of Bordeaux has provided the $\mathrm{PhD}$ grant for $\mathrm{ET}$.

\section{Notes and references}

¥ Synthesis. The synthesis is the same as previously described ${ }^{16 c}$ KNCS being replaced by KNCSe. Single-crystals were obtained, after few days, by slow diffusion of the iron solution through a methanol layer into the ligand solution, in a straight tube under inert atmosphere. Single-crystals are black needles. The dark-green powder is obtained by adding drop by drop, slowly, the ligand solution into the iron solution, under nitrogen flow. After filtration, the precipitate was washed with diethyl ether. Anal. Calcd for $\mathrm{C}_{42} \mathrm{H}_{28} \mathrm{FeN}_{6} \mathrm{Se}_{2}$ : C, 60.74; $\mathrm{H}, 3.39 ; \mathrm{N}, 10.12$. Found: $\mathrm{C}, 60.56 ; \mathrm{H}$, $3.45 ; \mathrm{N}, 9.69$

$\S$ Magnetic properties were measured using a SQUID magnetometer (Super Quantum Interference Device from Quantum Design) MPMS5 between 390 and $50 \mathrm{~K}$ in $10000 \mathrm{G}$ magnetic field, on $33.9 \mathrm{mg}$ of polycrystalline sample sealed in a polypropylene bag whose diamagnetic contribution is known Pascal's constants were used to estimate the diamagnetic correction related to the compound, which were subtracted from the experimental susceptibilities to give the molar paramagnetic susceptibilities $\left(\chi_{M}\right)$. The temperature was varied at the rate of 2 and $5 \mathrm{~K} \mathrm{~min}^{-1}$ in sweep mode. The single crystal measurement was performed on one crystal $(0.18 \mathrm{mg})$, fixed on a silicium sample holder perpendicular to the magnetic field whose diamagnetic contribution is known. Details including cycling reproduciblity and multiple cooling-rate measurements are available in ESI.

$\S \S$ Single-Crystal X-Ray Diffraction. Data collection was performed on a sealed $\mathrm{X}$-ray tube $(\mathrm{MoK} \alpha)$ Bruker-Nonius Kappa CCD. The computing data analysis was done with Olex2. ${ }^{25} \mathrm{C}_{42} \mathrm{H}_{28} \mathrm{FeN}_{6} \mathrm{Se}_{2} \cdot \mathrm{M}=830.47 \mathrm{~g} \cdot \mathrm{mol}^{-1}$. Crystal structure at $300 \mathrm{~K}$, monoclinic $\mathrm{P} 2_{1} / \mathrm{c}$ space group, $\mathrm{Z}=4, \mathrm{a}=15.7175(13) \AA \mathrm{A}, \mathrm{b}=$ 14.6860(13) $\AA, c=16.9957(13) \AA, \beta=93.399(3)^{\circ}, V=3916.2(6) \AA^{3} .59160$ collected reflections, 8154 unique and 4952 observed, $R_{\text {int }}=0.042,460$ refined parameters, refinement on $\mathrm{F}^{2}, \mathrm{R}_{\mathrm{obs}}=0.059, \mathrm{wR} 2_{\mathrm{obs}}=0.137, \mathrm{~S}=1.03$. Crysta structure at $230 \mathrm{~K}$, orthorhombic Pccn space group, $\mathrm{Z}=4$, $a=14.444$ (5) $\AA$, $b=$ 14.705(4) $\AA, c=17.595(4) \AA, V=3737.2(17) \AA^{3} .21670$ collected reflections, 2964 unique and 1612 observed, $R_{\text {int }}=0.055,231$ refined parameters refinement on $\mathrm{F}^{2}, \mathrm{R}_{\mathrm{obs}}=0.049$, $\mathrm{wR} 2_{\mathrm{obs}}=0.104, \mathrm{~S}=1.14$. CCDC 1531430 and 1531464 for the HS and LS crystal structures respectively.

1 (a) O. Kahn, C. Jay-Martinez, Science, 1998, 279, 44; (b) J.-F. Létard, P. Guionneau, L. Goux-Capes, Top. Curr. Chem., 2004, 235, 221; (c) P. Gütlich, A.B. Gaspar, Y. Garcia, Beilstein J. Org. Chem. 2013, 9, 342391; (d) A. Bousseksou, G. Molnár, L. Salmon, W. Nicolazzi, Chem. Soc. Rev., 2011, 40, 3313

2 M. M. Khusniyarov, Chem. Eur. J., 2016, 22, 15178.

3 S. Brooker, Chem. Soc. Rev., 2015, 44, 2880.

4 M. Shatruk, H. Phan, B.A. Chrisostomo, A. Suleimenova, Coord. Chem Rev., 2015, 289, 62.

5 M.A. Halcrow, Chem. Lett., 2014, 43, 1178.
6 (a) S. Hayami, T. Kawahara, G. Juhasz, K. Kawamura, K. Uehashi, O Sato, Y. Maeda, J. Radio. Nucl. Chem., 2003, 255(3), 443; (b) G.A. Graig, J. Sanchez Costa, O. Roubeau, S.J. Teat, G. Aromi, Chem. Eur. J., 2011, 17, 3120

7 J. Kröber, E. Codjovi, O. Kahn, F. Grolière, C. Jay, J. Am. Chem. Soc., 1993, 115, 9810

8 (a) O. Roubeau, Chem. Eur. J., 2012, 18, 15230; (b) G. Aromi, L.A. Barros, O. Roubeau, P. Gamez, Coord. Chem. Rev. 2011, 255, 485; (c) L. G. Lavrenova, O. G. Shakirova, Eur. J. Inorg. Chem., 2013, 670; 3.

9 (a) J.G. Haasnoot, G. Vos, W.L. Groeneveld, Z. Naturforsch, 1977, 32b, 1421; (b) J. Kröber, J.-P. Audière, R. Claude, E. Codjovi, O. Kahn, J.G. Haasnoot, F. Grolière, C. Jay, A. Bousseksou, J. Linarès, F. Varret, A. Gonthier-Vassal, Chem. Mater. 1994, 6, 1404.

10 (a) D. Qiu, L. Gu, X.-L. Sun, D.-H. Ren, Z.-G. Gu, Z. Lia, R. Soc. Chem. Adv., 2014, 4, 61313; (b) C. M. Quintero, G. Felix, I. Suleimanov, J. Sanchez Costa, G. Molnar, L. Salmon, W. Nicolazzi, A. Bousseksou, Beilstein J Nanotechnol., 2014, 5; (c) M. Gimenez-Marqués, M. Luisa Garcia-Sanz de Larrea, E. Coronado, J. Mater. Chem. C 2015, 3, 7946; (d) C. Bartual-Murgui, E. Natividad, O. Roubeau, J. Mater. Chem. C 2015, 3, 7916; (e) L. Moulet, N. Daro, S. Mornet, N. Vilar-Vidal, G. Chastanet, P. Guionneau, Chem. Commun., 2016, 52, 13213. (f) T. Zhao, L. Cuignet, M.M. Dîrtu, M. Wolff, V. Spasojevic, I. Boldog, A. Rotaru, Y. Garcia, C.J. Janiak, J. Mater. Chem. C, 2015, 3, 7802.

11 C. Lochenie, W. Bauer, A.P. Raillet, S. Schlamp, Y. Garcia, B. Weber, Inorg. Chem., 2014, 53, 11563.

12 P. Guionneau, Dalton Trans., 2014, 43, 382.

13 (a) I. Nemec, R. Herchel, Z. Trávníček, Dalton Trans., 2015, 44, 4474 (b) L.J. Kershaw Cook, R. Kulmaczewski, O. Cespedes, M.A. Halcrow, Chem. Eur. J., 2016, 22, 1789 ; (c) E. Milin, B. Benaicha, F. el Hajj, V. Patinec, S. Triki, M. marchivie, C.J. Gomez-Garcia, S. Pillet, Eur. J. Inorg. Chem. 2016, 5305.

14 B. Weber, W. Bauer, J. Obel, Angew. Chem. Int. Ed., 2008, 47, 10098.

15 S. Floquet, M.L. Boillot, E. Rivière, F. Varret, K. Boukheddaden, D. Morineau, Ph. Négrier, New. J. Chem., 2003, 27, 341.

16 (a) P. Guionneau, J.-F. Létard, D.S. Yuffit, D. Chasseau, J.A.K. Howard, A.E. Goeta, O. Kahn, J. Mater. Chem., 1999, 4, 985 ; (b) N. Paradis, F. Le Gac, P. Guionneau, A. Largeteau, D. S. Yufit, P. Rosa, J.F. Létard, G. Chastanet, Magnetochemistry, 2016, 2, 15; (c) J.F. Létard, P. Guionneau, E. Codjovi, O. Lavastre, G. Bravic, D. Chasseau, O. Kahn, J. Am. Chem. Soc., 1997, 119, 10861; (d) P. Guionneau, F. Le Gac, S. Lakhoufi, A. Kaiba, D. Chasseau, J.F. Létard, P. Négrier, D. Mondieg, J.A.K Howard, J.M. Léger, J. Phys. Cond. Matter, 2007, 19, 326211.

17 L. Capes, J.-F. Létard, O. Kahn, Chem. Eur. J., 2000, 6, 2246.

18 S. Zheng, M.A. Siegler, O. Roubeau, S. Bonnet, Inorg. Chem., 2014, 53, 13162.

19 A. Hauser, Coord. Chem. Rev. 1991, 111, 275.

20 J.-F. Létard, G. Chastanet, P. Guionneau, C. Desplanches, in Spin Crossover Materials: Properties and Applications, Ed. Malcom A. Halcrow, 2013, John Wiley \& sons, 475.

21 (a) M. Marchivie, P. Guionneau, J.-F. Létard, D. Chasseau, Acta Cryst., 2005, B61, 25; (b) S. Alvarez, J. Am. Chem. Soc., 2003, 125, 6795; (c) E. König, Prog. Inorg. Chem., 1987, 35, 527.

22 M.A. Halcrow, Chem. Soc. Rev., 2011, 40, 4119.

23 S. Lakhloufi, M. H. Lemée-Cailleau, G. Chastanet, P. Rosa, N. Daro, P. Guionneau, Phys. Chem. Chem. Phys., 2016, 18, 28307.

24 M.A. Spackman, D. Jayatilaka, CrystEngComm, 2009, 11, 19.

25 O.V. Dolomanov, L.J. Bourhis, R.J. Gildea, J.A.K. Howard, H. Puschmann, J. Appl Cryst., 2009, 42, 229. 